\title{
MEDIAÇÃO DE CONFLITOS E A BUSCA DA FELICIDADE NO CONTEXTO DOS DIREITOS HUMANOS
}

\section{CONFLICT MEDIATION AND THE PURSUIT OF HAPPINESS IN THE CONTEXT OF HUMAN RIGHTS}

\author{
${ }^{1}$ Carla Maria Franco Lameira Vitale
}

\section{RESUMO}

O presente trabalho objetiva contextualizar o princípio da busca da felicidade, instituto não positivado no ordenamento jurídico brasileiro, mas que tem sido utilizado para fundamentar importantes decisões. É previsto expressamente em diversos diplomas de direitos humanos e legislações estrangeiras, o que respalda a relevância do assunto. O conceito de felicidade é subjetivo, mas o fato é que o homem, em sua essência universal, a busca como forma de satisfação e prazer. Pretende, ainda, demonstrar que a mediação, como método adequado de resolução de conflitos e meio garantidor de acesso à justiça, pode ser instrumento eficaz para que a tão almejada felicidade seja atingida, na medida em que os envolvidos são estimulados a buscarem a solução que melhor atende aos anseios pessoais e, sobretudo, a dignidade da pessoa humana.

Palavras-chave: Busca da felicidade, Mediação, Direitos humanos

\begin{abstract}
This current work aims to contextualize the principle of the pursuit of happiness, institute that is not legalized in the Brazilian system, but it has been used to support important decisions. It is expressly provided in several human rights diplomas and international legislation, which supports the relevance of the subject. The concept of happiness is subjective, but the fact is that the man in his universal essence, search it as a form of satisfaction and pleasure. It also intends to demonstrate that mediation, as an appropriate method of resolving conflicts and guarantor way of access to justice can be an effective instrumet to achieve the desired happiness, to the extent that those involved are encouraged to seek the best solution to satisfies the personal desires and, above all, the dignity of the human person.
\end{abstract}

Keywords: Pursuit of happiness, Mediation, Human rights

\footnotetext{
${ }^{1}$ Mestranda em Direito pela Universidade Federal de Sergipe - UFS, Aracaju, Sergipe, Brasil. E-mail: tutortreinamento@gmail.com
} 


\section{INTRODUÇÃO}

A mediação, como método adequado de solução de controvérsias, assume hoje um lugar de destaque no cenário mundial, como forma de promoção da pacificação social.

Trata-se de um método eficaz de acesso à justiça, efetivada pelas próprias partes envolvidas, que são as verdadeiras protagonistas do conflito, com o alcance da justiça de cada um, já que permite o restabelecimento de relações rompidas após a controvérsia.

Dessa forma, busca-se abordar de que forma a mediação, que, inclusive, foi recentemente positivada em nosso ordenamento jurídico, pode ser instrumento apto para a obtenção do direito à busca da felicidade, tema que é objeto de algumas decisões e que merece destaque por já estar consagrado em diversos ordenamentos jurídicos.

Nessa perspectiva, o trabalho da mediação poderá ofertar um tratamento apropriado por se diferenciar na abordagem de ações e resultados, já que trata o conflito em sua forma mais ampla e alcança a pessoa humana.

A dignidade da pessoa humana, elevada a princípio fundamental da República pela Constituição Federal de 1988, pode ser alcançada através de mecanismos que promovam a satisfação do indivíduo na sua incessante busca pela felicidade, que já foi considerada um subprincípio daquele.

E o desafio que se aponta é demonstrar que dentre os métodos de solução de conflitos existentes, a mediação desponta como o mais eficaz na obtenção da satisfação pessoal, por refletir e buscar ações que levam em consideração a pessoa e, consequentemente, a busca pela felicidade.

Para a realização do presente trabalho, o método utilizado será essencialmente bibliográfico. A origem das informações obtidas partirá de conteúdos extraídos de livros e artigos disponibilizados em revistas e em meio eletrônico sobre a temática da pesquisa. Conforme salienta Gil (1999), a análise das informações tem como objetivo principal organizar os dados, a fim de analisar o tema que se evidencia.

O método analítico será o categórico dedutivo, isto é, partindo-se do geral para o específico, com resultados projetáveis para o universo.

O trabalho ora apresentado tem grande relevância jurídica e social, por ser a mediação, recentemente regulamentada pela Lei n. ${ }^{\circ}$ 13.140/2015, instrumento de efetivação da busca pela felicidade. 


\title{
1 MEDIAÇÃO DE CONFLITOS
}

\subsection{Conceito}

A mediação se destaca como método adequado de resolução de conflitos e é conceituada por vários estudiosos do assunto.

Destaca-se a abordagem de Gruspin (2000, p.13), médico e psicólogo, que expõe seu conceito sobre a mediação como: "um processo no qual uma terceira pessoa, neutra, o mediador, facilita a resolução de uma controvérsia ou disputa entre duas partes".

Moore (1998, p.28) assim a define:

\begin{abstract}
(...)interferência em uma negociação ou em um conflito de um terceira parte aceitável, tendo um poder de decisão limitado ou não-autoritário, e que ajuda as partes envolvidas a chegarem voluntariamente a um acordo, mutuamente aceitável com relação às questões em disputa. Além de lidar com questões fundamentais, a mediação pode também estabelecer ou fortalecer relacionamentos de confiança e respeito entre as partes ou encerrar relacionamentos de uma maneira que minimize os custos e danos psicológicos. (O processo de mediação - Estratégias práticas para resolução de conflitos)
\end{abstract}

O psicanalista e mediador Vezzulla (2006, p.69-70), apresenta o seguinte conceito de mediação:

\begin{abstract}
O procedimento privado e voluntário coordenado por um terceiro devidamente habilitado que orienta o seu trabalho para que se estabeleça uma comunicação cooperativa e respeitosa entre os participantes, com o objetivo de aprofundar a análise e a compreensão do relacionamento, das identidades, necessidades, motivações e emoções dos participantes, para que possam alcançar uma solução satisfatória dos problemas em que estão envolvidos.
\end{abstract}

Segundo Didier Júnior (2009, p.78),

\begin{abstract}
A mediação é uma técnica não-estatal de solução de conflitos, pela qual um terceiro se coloca entre os contendores e tenta conduzi-los à solução autocomposta. $\mathrm{O}$ mediador é um profissional qualificado que tenta fazer com que os próprios litigantes descubram as causas do problema e tentem removê-las. Trata-se de técnica para catalisar a autocomposição.
\end{abstract}

No entendimento de Bacellar (2012), a mediação, além de processo, é uma técnica de resolução de conflitos intermediada por um terceiro mediador. Tem como objetivo solucionar pacificamente as divergências entre pessoas, fortalecer suas relações e preservar os laços de confiança e os compromissos recíprocos que as vinculam. 
Um conceito técnico de mediação judicial é o de Yarn (1999 apud Gomma et al., 2013, p.85) que afirma ser a mediação judicial:

\begin{abstract}
Um processo autocompositivo segundo o qual as partes em disputa são auxiliadas por uma terceira parte, neutra ao conflito, ou um painel de pessoas sem interesse na causa, para auxiliá-las a chegar a uma composição. Trata-se de uma negociação assistida ou facilitada por um ou mais terceiros na qual se desenvolve processo composto por vários atos procedimentais pelos quais o(s) terceiro(s) imparcial(is) facilita(m) a negociação entre pessoas em conflito, habilitando-as a melhor compreender suas posições e a encontrar soluções que se compatibilizam aos seus interesses e necessidades.
\end{abstract}

De acordo com o parágrafo primeiro, art. $1^{\circ}$ da Lei de Mediação: "Considera-se mediação a atividade técnica exercida por terceiro imparcial sem poder decisório, que, escolhido ou aceito pelas partes, as auxilia e estimula a identificar ou desenvolver soluções consensuais para a controvérsia”.(BRASIL, Lei n. ${ }^{\circ}$ 13.140, de 26 de junho de 2015, 2015).

Ainda em conformidade com a referida Lei de Mediação, esse método possui natureza extrajudicial ou judicial e pode contar com a atuação de profissionais de diversas áreas, como psicólogos, advogados, psiquiatras, assistentes sociais. Tem como característica a voluntariedade, pois as partes não são obrigadas a participar de uma mediação. A aplicação poderá ser feita em diversas áreas, como a cível, comercial, trabalhista, ambiental e familiar.

Como se vê, a participação dos envolvidos é privilegiada, uma vez que são os verdadeiros protagonistas da sessão. O mediador, nada mais é do que um facilitador do diálogo entre as partes, que tem o intuito de restabelecer a comunicação entre os participantes ou torná-la mais produtiva. As partes serão estimuladas a refletir sobre os seus reais interesses, ou seja, aquilo que está por trás da pretensão exposta, que é até mais importante do que esta.

Pretende-se, com a mediação, resolver o conflito e todas as suas possíveis ramificações. A ideia é que as partes pensem nas possibilidades de soluções e, dentre elas, a que melhor atende aos interesses de todos os envolvidos.

De acordo com Warat (2001, p. 9):

(...) a função da mediação é de intervir basicamente no aspecto emocional, buscando transformar uma relação conflituosa em uma relação saudável, auxiliando as partes a compreender o conflito de forma mais aprofundada (o que implica compreender os seus próprios desejos e interesses), para que, com isso seja possível converter um comprometimento negativo em um comprometimento positivo ou aumentar o nível de cooperação entre as partes.

A mediação proporciona um aprendizado que auxilia na formação do indivíduo como cidadão responsável por seus atos e consequências correlatas, ressalta a 
responsabilidade de cada um, a adequação das próprias escolhas, a valorização a si e ao próximo, a cooperação e a tolerância.

Assim, a mediação deve ser vista como um paradigma na resolução dos conflitos, já que trabalha as questões postas em discussão de uma maneira mais ampla e com maior potencial de transformar a sociedade, de maneira a educá-la para que sejamos capazes de resolver eventuais conflitos de maneira equilibrada e mais satisfatória.

Dessa forma, o enfoque da mediação são os casos provenientes de relações continuadas, como as relações familiares, empresariais, trabalhistas ou de vizinhança, uma vez que proporciona o restabelecimento e os interesses e sentimentos podem ser melhor trabalhados.

\subsection{Mediação como Método Adequado de Resolução de Conflitos}

Os Métodos Alternativos de Resolução de Conflitos, também conhecidos como meios de Resolução Apropriada de Disputa(RAD) são garantias constitucionais de acesso à justiça, que buscam o atendimento da efetividade de direitos sob uma visão humana, haja vista não se prenderem a soluções estritamente técnico-jurídicas. São eles: negociação, conciliação, mediação e arbitragem.

Convém ressaltar, que a depender do seu objeto, capacidade de entendimento entre as partes, dentre outros fatores, os conflitos intersubjetivos podem adquirir as mais variadas feições.

Negociação é um método de solução de conflitos em que as próprias partes resolvem a desavença, sem que haja a necessidade de intervenção ou auxílio de uma outra pessoa.

Fisher et al. (2005) que fazem parte do projeto de negociação de Harvard, citado no livro Como Chegar ao Sim, conceituam a negociação como a Arte da Persuasão. Dessa forma, para que haja sucesso em uma negociação é preciso que alguns fatores coexistam, tais como, equilíbrio entre a razão e emoção, sagacidade e confiabilidade.

A arbitragem é um método voluntário, em que também há a intervenção de um terceiro, no entanto, diferente do que ocorre na mediação e conciliação, este não terá a função de facilitar o diálogo (apesar disso sempre ser recomendável e possível em qualquer procedimento), mas o de colher provas e decidir mediante laudo ou sentença arbitral irrecorrível. 
Na conciliação, a resolução de controvérsias é administrada por um conciliador, a quem compete aproximá-las, controlar as negociações, aparar arestas, sugerir e formular propostas, apontar vantagens e desvantagens. O objetivo do conciliador é o de estabelecer uma composição do litígio pelas partes. Apresenta como características: administração do conflito por um terceiro imparcial e a possibilidade do conciliador poder sugerir um possível acordo.

Bacellar (2012) define a conciliação como um processo técnico, onde um terceiro imparcial ouve as partes, orienta-as, auxilia com perguntas, propostas e sugestões a encontrar soluções que atendam aos interesses dos envolvidos e as materializa em um acordo.

E, como já conceituado, temos a mediação como método de resolução de conflitos que se destaca dos demais pelo empoderamento das partes na solução dos seus próprios conflitos, já que tem como objetivo zelar pelos interesses e sentimentos dos envolvidos, em busca da satisfação plena dos participantes e da pacificação social.

Ainda segundo Roberto Bacellar (2012), a mediação tem como objetivo solucionar pacificamente as divergências entre pessoas, fortalecer suas relações e preservar os laços de confiança e os compromissos recíprocos que as vinculam. As soluções são construídas pelos próprios envolvidos no conflito, com o intuito de superá-lo de forma construtiva, o que se apresenta muito mais satisfatório e duradouro para as partes.

Como evidencia Sarlet (2006), dentro do conteúdo da dignidade humana está a garantia a uma identidade pessoal dos indivíduos, bem como o direito de autodeterminação sobre os assuntos que dizem respeito a sua esfera particular.

E o ilustre doutrinador Capelletti (1988) evidencia o sentido da mediação, ao afirmar que a aproximação do cidadão com o Judiciário e sua participação ativa na solução do litígio, privilegio o princípio da dignidade humana, por superar a formalidade excessiva do processo judicial e primar pelo diálogo entre os cidadãos. E a moderna doutrina, há muito, afirma que num sistema jurídico moderno e igualitário o acesso à justiça tornou-se o mais básico dos direitos humanos.

Assim, dentre os métodos alternativos de solução de conflitos, é a mediação, o que mais se aproxima da plena satisfação dos envolvidos, já que trabalha as necessidades, interesses e sentimentos das partes, e as empodera em busca da solução mais justa, como instrumento da dignidade humana. 


\title{
2 MEDIAÇÃO DE CONFLITOS E A BUSCA DA FELICIDADE
}

\subsection{Conceito de Felicidade}

A busca da felicidade tem sido fundamento de recentes decisões dos nossos tribunais, além de constar em legislações estrangeiras, bem como em diplomas internacionais, o que nos faz refletir sobre o conceito de felicidade.

O termo felicidade é conceituado no Dicionário Houaiss da Língua Portuguesa (2004) como: "1. qualidade ou estado de feliz, estado de uma consciência plenamente satisfeita, satisfação, contentamento, bem-estar; 2. boa fortuna, sorte; 3. bom êxito, acerto, sucesso".

A filosofia é uma importante fonte de discussão acerca da felicidade. Inúmeros filósofos cuidaram de traçar conceitos acerca desse tema.

Segundo Aristóteles (2009, p.59):

\begin{abstract}
A felicidade é a finalidade da natureza humana como dádiva dos deuses, a felicidade é perfeita. A felicidade é um bem supremo que a existência humana deseja e persegue, de modo que a felicidade depende dos bens exteriores para ser realizada. Deste modo, é na busca da felicidade que se justifica a boa ação humana, sendo os outros bens meios para atingir o bem maior felicidade".
\end{abstract}

Para o psicanalista francês Lacan (2008, p.341), felicidade é “algo que se busca, que se demanda".

Ressalte-se o entendimento de Lama (2000, p.9) sobre a felicidade:

Para mim o próprio objetivo da vida é perseguir a felicidade. Isso está claro. Se acreditamos em religião, ou não; se acreditamos nesta religião ou naquela; todos estamos procurando algo melhor na vida. Por isso, para mim, o próprio movimento da nossa vida é no sentido da felicidade[...]

Teixeira (2012, p.15), introduz a sua obra da seguinte forma: "O que é felicidade? Depende. De onde e quando você nasceu. Da sua formação intelectual. Da sua profissão. Depende, a rigor, de tanta coisa que é quase inútil procurar uma resposta universal. Quase".

Merecem relevância também os questionamentos sobre felicidade trazidos pelo economista Giannetti (2012, p.10):

Quais as relações entre o processo civilizatório e a felicidade humana? Os benefícios da civilização são tangíveis e passíveis de mensuração. Um conjunto expressivo de indicadores biomédicos, sociais e econômicos atesta os ganhos objetivos em termos de longevidade, saúde, escolarização, acesso a bens de consume e tantos outros feitos derivados do progresso científico e do aumento da produtividade. Mas quais 


\begin{abstract}
têm sido os efeitos de todas essas brilhantes conquistas no tocante à felicidade, ou seja, tendo em vista a nossa satisfação em viver e o grau de realização que esperamos e alcançamos em nossas vidas? Até que ponto a civilização moderna tem promovido ou dificultado a busca da felicidade? [...]
\end{abstract}

Ainda o mesmo autor, Giannetti (2012, p.28), acrescenta que: “[...] o propósito terreno das pessoas de carne e osso em qualquer lugar do planeta é alcançar a felicidade e fazer o melhor de que são capazes de suas vidas”.

Em que pese haver diversas definições e dúvidas acerca da felicidade, cada pessoa a avalia de acordo com as suas aspirações, modo de vida, necessidades e expectativas.

Dessa forma, ao aderir ao conceito de felicidade como norteador do ordenamento jurídico, demonstra-se um resgate à essência do ser humano, que naturalmente a tem como objetivo a ser alcançado.

\title{
2.2 A Busca da Felicidade como Principio Fundamental X Direitos Humanos
}

Os direitos humanos são definidos por Ramos (2015, p.38) como "um conjunto mínimo de direitos necessários para assegurar uma vida do ser humano baseada na liberdade, igualdade e na dignidade".

Ainda segundo Ramos (2015, p.40), a doutrina e o direito positivo utiliza diversos termos e expressões para traduzir o conceito dos chamados "direitos humanos", tais como "direitos fundamentais", "liberdades públicas", "direitos da pessoa humana", "direitos do homem", "direitos da pessoa", "direitos individuais", "direitos fundamentais da pessoa humana", "direitos públicos subjetivos". Como exemplo, cita a nossa Constituição Federal de 1988 em diversos artigos, além de outros diplomas internacionais como a Declaração Americana de Direitos e Deveres do Homem de 1948, a Declaração Universal de Direitos Humanos e a Carta da Organização das Nações Unidas.

Os direitos humanos, ao serem reconhecidos e positivados nas Constituições, leis e tratados internacionais passam a ser chamados de direitos fundamentais e dessa forma mantém íntima conexão com aqueles.

Impende situar a busca da felicidade como um princípio fundamental no contexto da evolução dos direitos humanos.

Percebe-se que na evolução das gerações dos direitos fundamentais, conforme Sarlet (2012, p.79), o Estado, na primeira fase, deveria abster-se de atuar, já que o direito à liberdade e a vontade individual predominavam sobre os interesses estatais. Num segundo 
momento, em decorrência dos abusos ocorridos com a industrialização, especialmente quanto aos direitos dos trabalhadores, passou-se a exigir maior atuação do Estado na defesa da dignidade da pessoa humana, período denominado de Estado Social, no qual foram assegurados direitos coletivos e individuais da humanidade.

Dessa forma, surge o Estado intervencionista e os direitos sociais, consagrados no art. $6^{\circ}$ da Constituição Federal Brasileira de 1988, foram evidenciados e a sociedade passou a cobrá-los através de políticas públicas.

Nesse contexto, o direito à busca da felicidade surge como uma decorrência dos direitos sociais, a ser buscado por cada um.

O renomado doutrinador Lenza (2012, p.54), reconhece o direito à felicidade como consequência natural dos direitos fundamentais de terceira geração, já que "marcados pela alteração da sociedade por profundas mudanças na comunidade internacional (sociedade de massa, crescente desenvolvimento tecnológico e científico), identificando-se profundas alterações nas relações econômico sociais".

No ordenamento jurídico pátrio não há previsão expressa desse direito. No entanto, tanto o Senado da República como a Câmara dos Deputados já discutiram propostas de emenda constitucional, de iniciativa do Senador Cristovam Buarque e da Deputada Manuela D’Ávila, a fim de inserir o direito à busca da felicidade no rol art. $6^{\circ}$ da Constituição Federal e como objetivo fundamental da República Federativa do Brasil, respectivamente.

Em suas justificativas às propostas 19/2010 513/210 (Câmara Federal), ambos parlamentares utilizaram como fundamentação o seguinte:

\footnotetext{
Na Declaração de direitos da Virgínia (EUA, 1776), outorgava-se aos homens o direito de buscar e conquistar a felicidade; na Declaração dos Direitos do Homem e do Cidadão (França, 1789) há a primeira noção coletiva de felicidade, determinando-se que as reivindicações dos indivíduos sempre se voltarão à felicidade geral. Hoje, o preâmbulo da Carta Francesa de 1958 consagra a adesão do povo francês aos Direitos Humanos consagrados na Delcaração de 1789, dentre os quais se inclui toda a evidência, à felicidade geral ali preconizada.
}

Ocorre que, em que pese terem sido aprovados pela Comissão de Constituição e Justiça, ambos foram arquivados pelo término da legislatura, em dezembro de 2014.

Importante salientar que o Supremo Tribunal Federal e o Superior Tribunal de Justiça têm fundamentado suas decisões na busca da felicidade e a reconhece, inclusive, como direito fundamental.

Segundo o voto proferido pelo relator Ministro Celso de Mello, no Recurso Extraordinário 477.554/MG, que trata sobre união civil de pessoas do mesmo sexo: 
O afeto como valor jurídico impregnado de natureza constitucional: a valorização desse novo paradigma como núcleo conformador do conceito de família - o direito à busca da felicidade, verdadeiro postulado constitucional implícito e expressão de uma idéia-força que deriva do princípio da essencial dignidade da pessoa humana alguns precedentes do Supremo Tribunal Federal e da Suprema Corte Americana sobre o direito fundamental à busca da felicidade[...]

O ministro Carlos Velloso assim se pronunciou no Agravo de Instrumento de n. ${ }^{\circ}$

548.146/AM:

[...] uma das razões mais relevantes para a existência do direito está na realização do que foi acentuado na Declaração da Independência dos Estados Unidos da América, de 1776, o direito do homem de buscar a felicidade. Noutras palavras, o direito não existe como forma de tornar amarga a vida dos seus destinatários, senão de fazê-la feliz.

Da mesma forma, o voto do Ministro Celso de Mello que, ao julgar a questão das pesquisas com células-tronco embrionárias, na Ação Declaratória de Inconstitucionalidade de

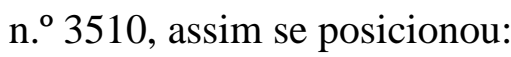

Permitirá a esses milhões de brasileiros, que hoje sofrem e que hoje se acham postos à margem da vida, o exercício concreto de um direito básico e inalienável que é o direito à busca da felicidade e também o direito de viver com dignidade, direito de que ninguém, absolutamente ninguém, pode ser privado.

Em julgamento do Recurso Especial 1157273/RN, onde foi relatora a Ministra Nancy Andrighi, houve o seguinte pronunciamento:

\begin{abstract}
Uma sociedade que apresenta como elemento estrutural a monogamia não pode atenuar o dever de fidelidade, que integra o conceito de lealdade, para o fim de inserir no âmbito do Direito de Família relações afetivas paralelas e, por consequência, desleais, sem descurar que o núcleo familiar contemporâneo tem como escopo a busca da realização de seus integrantes, vale dizer, a busca da felicidade (...) Ao analisar as lides que apresentam paralelismo afetivo, deve o juiz, atento às peculiaridades multifacetadas apresentadas em cada caso, decidir com base na dignidade da pessoa humana, na solidariedade, na afetividade, na busca da felicidade, na liberdade, na igualdade, bem assim, com redobrada atenção ao primado da monogamia, com os pés fincados no princípio da eticidade. - Emprestar aos novos arranjos familiares, de uma forma linear, os efeitos jurídicos inerentes à união estável, implicaria julgar contra o que dispõe a lei.
\end{abstract}

É imperioso ressaltar que a felicidade está consagrada em diversos ordenamentos jurídicos. Na Declaração de Independência dos Estados Unidos, a felicidade consta como direito inalienável. A Constituição do Japão, em seu art.13 preceitua que todas as pessoas têm direito à busca pela felicidade e que o Estado deve garantir as condições para sua obtenção. $\mathrm{O}$ art. 10 da Constituição da Coréia do Sul explicita que todos tem o direito a alcançar a 
felicidade e o Estado deve confirmar e assegurar os direitos humanos dos indivíduos. A Carta Francesa de 1958, em seu preâmbulo, também a menciona.

O preâmbulo da Declaração Americana dos Direitos e Deveres do Homem de 1948, assim dispõe:

Considerando: Que os povos americanos dignificaram a pessoa humana e que suas constituições nacionais reconhecem que as instituições jurídicas e políticas, que regem a vida em sociedade, têm como finalidade principal a proteção dos direitos essenciais do homem e a criação de circunstâncias que lhe permitam progredir espiritual e materialmente e alcançar a felicidade(...)

A Organização das Nações Unidas (ONU), em sua Assembleia Geral ocorrida em 13 de julho de 2011, classifica a busca da felicidade como "meta fundamental humana", nos seguintes termos:

\footnotetext{
(...)Reconhecendo a necessidade de promover o desenvolvimento sustentável e atingir as Metas de Desenvolvimento do Milênio, 1. Convida os Estados Membros a perseguirem a elaboração de indicadores adicionais que melhor capturem a importância da busca da felicidade e do bem-estar no desenvolvimento, com vistas a orientar suas políticas públicas.(...)
}

O fato é que a busca da felicidade, assim como qualquer outro direito fundamental, é condição inerente a todo ser humano e que o Estado Democrático de Direito deve promover os meios de promover a sua obtenção.

\subsection{Alcance do Princípio da Busca da Felicidade na Mediação}

A Felicidade, como bem pontua Schafranski (2012), decorre do princípio da dignidade da pessoa humana, por se tratar de uma aspiração universal, e a Organização das Nações Unidas (ONU) a reconheceu como direito humano fundamental, constituindo objetivo fundamental de toda e qualquer política pública a ser adotada pelo Estado.

O objetivo da mediação é promover a satisfação das partes, o que pode ser atingido através de um acordo justo para todos. Porém, há outros benefícios advindos deste método, além do acordo final.

Ao trabalhar a comunicação e o entendimento das partes, outras finalidades são atingidas, a exemplo da melhoria do relacionamento entre os envolvidos e o crescimento pessoal.

Instrumento de pacificação social, a mediação promove a autonomia do indivíduo, a cidadania e a concretização da democracia, princípio basilar do estado, pois tem a virtude de educar para as diferenças entre os indivíduos e estimular a tomada de decisões sem a 
intervenção de terceiros que imponham suas decisões aos litigantes, representando um verdadeiro instrumento de exercício da cidadania, de acesso à justiça e de obtenção da felicidade.

Assevera Muniz (2008, p. 56):

\begin{abstract}
Atualmente quando falamos de cidadania nos referimos ao principal fundamento da finalidade do Estado democrático de direito, cujos pilares de sustentação encontramse na admissão, na garantia e na efetividade dos direito fundamentais da pessoa humana, ou seja, o estado deve possibilitar aos seus habitantes a possibilidade de desenvolvimento pleno através do exercício de um grande conjunto de direitos e deveres.
\end{abstract}

Uma mediação bem trabalhada pode tornar os envolvidos mais aptos a examinar questões, negociar interesses e ser capazes, sobretudo, de enfrentar eventuais conflitos futuros de forma eficaz.

Conforme salienta Fiorelli (2008, p. 44). "Na mediação, migra-se da barganha por posições, que apenas gera emoções negativas, para o reconhecimento dos interesses e busca de opções por trás das posições manifestas".

Parte-se de um plano individual para algo maior, que é educar a sociedade para que os cidadãos estejam preparados para lidar com situações adversas sem a necessidade de se buscar o judiciário, o que trará como consequência a satisfação pessoal e promoverá uma felicidade coletiva.

Conforme preceitua Araújo (2000, p.74):

\footnotetext{
Não se concebe a ideia de que o Estado Moderno deva buscar um caminho diferente daquele que pressupõe a felicidade de seus componentes. O homem se organiza para obter felicidade. Submete-se ao regramento do Estado, aceita suas regras, paga os impostos, limita-se, sabendo, no entanto, que os fins dessa associação só podem levar à busca da felicidade.
}

Nesse toar, o trabalho desenvolvido através da mediação poderá ofertar um tratamento bem mais adequado e diferenciado por abordar o conflito em sua forma mais ampla, a fim de alcançar a pessoa humana e a tão almejada felicidade. 


\section{CONCLUSÃO}

É fundamental a percepção de que o fim da mediação não é tão somente o acordo, mas, principalmente, a transformação do conflito, já que este não é fruto de situações objetivas, mas da maneira como as pessoas enxergam uma situação e reagem a ela, de forma que se torna possível alterar o próprio conflito a partir da modificação do modo como as partes envolvidas o percebem. Trata-se de uma percepção e compreensão dos interesses e sentimentos, e não de uma simples negociação de valores.

Negociar com base em princípios significa valorizar os interesses comuns e a preservação do respeito mútuo. Aproveitar o conflito ocasionado pela divergência de interesses, ideias e visões para construir novas realidades mais produtivas para todos os envolvidos.

Nesse contexto, destaca-se o princípio da busca da felicidade, classificada por alguns doutrinadores e juristas como um direito fundamental implícito, ao tempo em que outros defendem sua positivação no rol desses direitos pela sua importância reconhecida desde a proclamação da Declaração de Direitos Humanos, com raiz histórica na própria Declaração de Independência dos Estados Unidos da América, em 04 de julho de 1776 e por ser indispensável à vida humana.

Dessa forma a felicidade ou a sua busca faz parte do conjunto de aspirações dos seres humanos e sendo o conflito parte do desenvolvimento da humanidade, resolvê-lo através da mediação é um paradigma que pode ser desenvolvido para garantir um efetivo acesso à justiça.

Além de atingir resultados mais duradouros e mudar a cultura existente de que apenas a justiça estatal possui a solução para os problemas, mostra que estes podem ser resolvidos através do diálogo e gerar mais harmonia e satisfação aos envolvidos.

Pretende-se, com isso, educar a sociedade para que as pessoas sejam capazes de dirimir seus próprios conflitos e, dessa forma, torná-las mais felizes.

\section{REFERÊNCIAS}

ARAÚJO, Luiz Alberto David. A Proteção Constitucional do Transexual. São Paulo: Editora Saraiva, 2000.

ARISTÓTELES. Ética a Nicômaco. Tradução de Edson Bini. 3 ed. Bauru: Edipro, 2009. 
ASSEMBLEIA GERAL DA ONU. 65 áSessão. 13 de julho de 2011. Felicidade em direção a uma abordagem holística para o desenvolvimento. Disponível em:

http://www.visãofuturo.org.br/informativo/2011/Agosto/Resolução\%20da\%20 ONU\%20Promove\%20Indicadores\%20de\%20Felicidade.pdf. Acesso em 09 ago. 2015.

AZEVEDO, André Gomma de (Org.). Manual de mediação judicial. Brasília, DF: Ministério da Justiça e Programa das Nações Unidas para o Desenvolvimento (PNUD), 2013.

BACELLAR, Roberto Portugal. Mediação e Arbitragem. São Paulo: Ed. Saraiva, 2012.

BRASIL. Lei n. ${ }^{\circ}$ 13.140, de 26 de junho de 2015. Disponível em: <https://www.planalto.gov.br/ccivil_03/_Ato2015-2018/2015/Lei/L13140.htm>. Acesso em: 08 jul. 2015.

BRASIL. Supremo Tribunal Federal. Segunda Turma. Recurso Extraordinário n. 477554. Recorrentes: Carmem Mello de Aquino Neta, representada por Elisabeth Alves Cabral e outros. Recorrido: Instituto de Previdência dos Servidores do Estado de Minas Gerais - IPSEMG Relator: Ministro Celso de Mello. DJe-164. Disponível em:

$<$ http://stf.jusbrasil.com.br/jurisprudencia/20623277/agreg-no-recurso-extraordinario-re477554-mg-stf $>$. Acesso em: 08 jul. 2015.

BRASIL. Supremo Tribunal Federal. Primeira Turma. Agravo de Instrumento n. ${ }^{\circ}$ 548.146. Agravante: Estado do Amazonas. Agravados: PGE-AM, Marcelo Augusto A. Da Cunha, Zedequias Rodrigues Da Silva, Aline Maria Pereira Mendonça Landim e outros Relator: Ministro Carlos Velloso. DJ 10/02/2006. Disponível em:

$\langle$ https://www.stf.jus.br/arquivo/djEletronico/DJE_20090528_099.pdf $>$. Acesso em: 08jul. 2015.

BRASIL. Supremo Tribunal Federal. Segunda Turma. Ação Direta de Inconstitucionalidade n. ${ }^{\circ}$ 3510. Acionante: Procurador Geral da República. Acionados: Presidente da República e outros. Relator: Carlos Ayres de Britto. DJe-096 Disponível em: $<$ http://stf.jusbrasil.com.br/jurisprudencia/14720566/acao-direta-de-inconstitucionalidade-adi3510-df $>$. Acesso em: 08jul. 2015.

BRASIL. Superior Tribunal de Justiça. Terceira Turma. Recurso Especial n. 1157273. Recorrente: D A DE O. Recorrido: A L C G e outros. Relator: Ministra Nancy Andrighi. DJe 07/06/2010. Disponível em: < http://stj.jusbrasil.com.br/jurisprudencia/14339099/recursoespecial-resp-1157273-rn-2009-0189223-0/inteiro-teor-14339100>. Acesso em: 08jul. 2015. 
BRASIL. Senado Federal. Proposta de Emenda à Constituição n. ${ }^{\circ} 19$ de 2010. Autor: Senador Cristovam Buarque. Data de apresentação: 07-07-2010. Arquivada: 26-12-2014. Disponível em: $<$ http://www.senado.gov.br/atividade/materia/detalhes.asp?p_cod_mate=97622 $>$. Acesso em: 08jul. 2015.

BRASIL. Câmara Federal. Proposta de Emenda à Constituição n. 513 de 2010. Autor: Deputada Manuela D’Ávila. Data de apresentação: 04-08-2010. Arquivada: 31-01-2015. Disponível em:

〈http://www.camara.gov.br/proposicoesWeb/fichadetramitacao?idProposicao=484478 $>$.

Acesso em: 08jul. 2015.

CAPPELletti, Mauro et al. Acesso à justiça. Tradução de Ellen Gracie Nortleet. Porto Alegre: Fabris, 1988.

DECLARAÇÃO AMERICANA DOS DIREITOS E DEVERES DO HOMEM. Disponível em < http://www.cidh.oas.org/basicos/portugues/b.Declaracao_Americana.htm $>$. Acesso em 09ago.2015.

DIDIER JR. Fredie. Curso de Direito Processual Civil: Teoria Geral do Processo e Processo de Conhecimento. Vol.1. 11ª edição. Salvador: Editora Podium, 2009.

FIORELLI, José Osmir et al. Mediação e solução de conflitos. Teoria e prática. São Paulo: Atlas, 2008.

FISHER, Roger et al. Como chegar ao sim: a negociação de acordos sem concessões. Tradução de Vera Ribeiro e Ana Luiza Borges. Rio de Janeiro: Ed Imago, 2005.

GIANNETTI, Eduardo. Felicidade. Diálogos sobre o bem estar da civilização. São Paulo: Companhia das Letras, 2002. Disponível em: <http://baixardownload.jegueajato.com/Eduardo\%20Giannetti/Felicidade\%20(461)/Felicidade\%20$\% 20$ Eduardo\%20Giannetti.pdf> Acesso em: 10ago.2015.

GIL, Antônio. C. Métodos e técnicas de pesquisa social. São Paulo: Atlas, 1999.

GRUNSPUN, Haim. Mediação familiar: o mediador e a separação de casais com filhos. São Paulo: LTr, 2000. 
HOUAISS, A. Dicionário Houaiss da Língua Portuguesa. Rio de Janeiro: Rev. Objetiva, 2004.

LACAN, Jaques- Seminário Livro 7: A ética da psicanálise - 1959-1960/ Jacques Lacan; texto estabelecido por Jacques- Alain Miller; [versão brasileira Antônio Quinet] - Rio de Janeiro: Jorge Zahar, 2008.

LAMA, Dalai; CUTLER Howard C. A Arte da Felicidade. Um Manual para a Vida. Tradução de Waldéa Barcellos. São Paulo: Livraria Martins Fontes Editora Ltda, 2000.

LENZA, Pedro. Direito Constitucional Esquematizado. $16^{\mathrm{a}}$ ed. São Paulo: Saraiva, 2012.

MOORE, Cristopher W. O Processo de Mediação: estratégias práticas para a resolução de conflitos; trad. Magda França Lopes - 2 edição - Porto Alegre: Ed. Artmed, 1999.

RAMOS, André de Carvalho. Teoria Geral dos Direitos Humanos na ordem internacional. 5 ed. São Paulo: Saraiva, 2015.

SARLET, Ingo Wolfgang. A eficácia dos direitos fundamentais, 3 ed. Porto Alegre: Livraria do Advogado, 2006.

SCHAFRANSKI, Marcelo. Medicina da Felicidade. São Paulo: Matrix Editora, 2012. SERPA,

Maria de Nazareth. Teoria e Prática da mediação de conflitos. Rio de Janeiro:

Lúmen Júris, 1999.

TEIXEIRA, Alexandre. Felicidade S.A. Por que a satisfação com o trabalho é a utopia possível para o século 21. Porto Alegre: Arquipélago Editorial Ltda, 2012.

VASCONCELOS, Carlos Eduardo. Mediação de Conflitos e Práticas Restaurativas. São Paulo: Ed. Método, 2008.

VezZulla, Juan Carlos. Adolescentes, Família, Escola e Lei. A Mediação de Conflitos. Lisboa: Comunicação, 2006.

WARAT, Luis Alberto. O Ofício do Mediador. Florianópolis: Habitus, 2001. 